\title{
CSF goes astray no matter what is in the way: occipital intradiploic pseudomeningocele and de novo syringomyelia following foramen magnum decompression for Chiari I malformation in a pediatric patient
}

\begin{abstract}
Arthur R. Kurzbuch, MD, ${ }^{1,2}$ and Shailendra Magdum, MD'
'Department of Pediatric Neurosurgery, Oxford University Hospitals NHS Foundation Trust, John Radcliffe Hospital, Oxford, United Kingdom; and '2Service de Neurochirurgie, Hôpital du Valais, Centre Hospitalier du Valais Romand (CHVR), Hôpital de Sion, Switzerland

Nontraumatic intradiploic pseudomeningoceles and de novo syringomyelia formation are very rare entities. The authors have previously reported the case of a 4-year-old girl who underwent foramen magnum decompression without dural closure for Chiari I malformation. Three years after the operation an intradiploic pseudomeningocele was documented, but the patient was lost to follow-up without undergoing revision surgery. Four years later, at the age of 11 years, the patient returned for treatment of intensifying symptoms. Radiological imaging then showed an increase in the size of the intradiploic pseudomeningocele and a new cervical syrinx. The patient underwent a first revision surgery in which a part of the internal layer of the occipital bone was removed and arachnoid scar lysis was performed. Two months later the syrinx had worsened, and in a second revision surgery a pseudomeningocele-peritoneal shunt was placed. Here, the authors describe what is to their knowledge the first case of an intradiploic pseudomeningocele and de novo syringomyelia formation following Chiari I decompressive surgery.
\end{abstract}

https://thejns.org/doi/abs/10.3171/2019.12.PEDS19427

KEYWORDS Chiari I malformation; foramen magnum decompression; intradiploic; syringomyelia; iatrogenic; complication

$\mathrm{M}$ OST cases of the rarely occurring occipital intradiploic pseudomeningoceles are of traumatic or idiopathic origin, $1,5,17,27$ and only a few reported cases have occurred postoperatively.,11,23,24,28,31 Postoperative development of syringomyelia has been mainly described following spinal CSF drainage, $, 14,26,30$ and anecdotally after pleural effusion aspiration ${ }^{32}$ and after surgery for spontaneous subdural hematoma. ${ }^{2}$ There is to our knowledge only one previous study of de novo syrinx formation, which included 7 pediatric patients presenting with de novo syrinx after decompressive surgery for Chiari I malformation. ${ }^{25}$ We have previously reported the case of a 4-year-old girl who had developed an occipital intradiploic pseudomeningocele following decompressive surgery for Chiari I malformation without dural closure. After under- going radiological imaging, this patient was lost to followup without having revision surgery. ${ }^{19}$ Then, after 4 years of loss to follow-up, she presented with an increase in the size of her intradiploic pseudomeningocele and a new cervical syrinx. We herein report the surgical revision performed in this patient and discuss possible underlying causes of both complications. To our knowledge no case of iatrogenic intradiploic pseudomeningocele and de novo formation of a syrinx after surgical treatment for Chiari I malformation has been described previously.

\section{Case Report}

History and Examination

This female patient first presented at the age of 3 years 


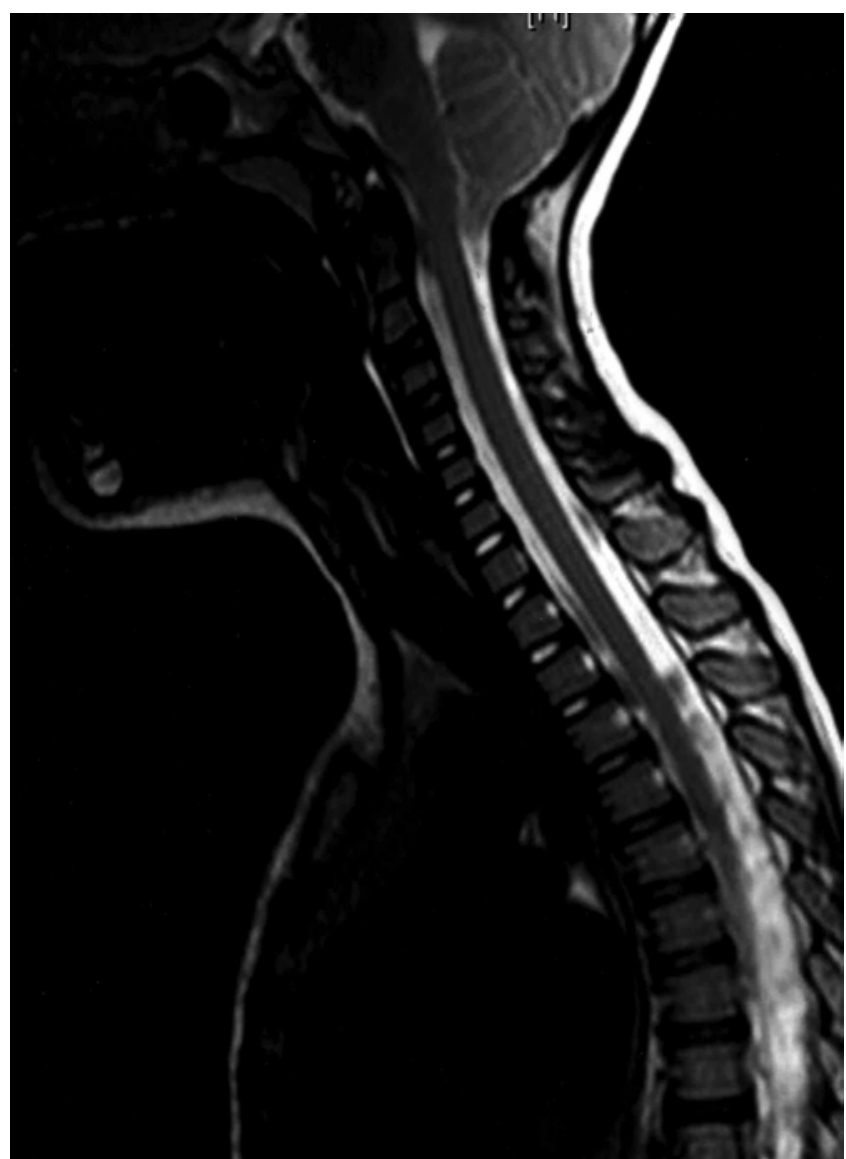

FIG. 1. Sagittal T2-weighted MR image showing the patient's Chiari I malformation (preoperative).

with complaints of headache, pins and needles predominantly in her upper limbs, and hypersensitivity to heat. One year later, at the age of 4 years, she underwent an MRI examination that showed a Chiari I malformation with the cerebellar tonsils descending to $\mathrm{C} 2$ but without a syrinx (Fig. 1). The MRI did not show signs of hydrocephalus. The patient's neurological status was normal. Foramen magnum decompression with a limited suboccipital craniectomy of $2.5 \times 1.5 \mathrm{~cm}$ and partial resection of the posterior arch of $\mathrm{C} 1$ was performed, followed by a wide durotomy and opening of the arachnoid. While the dura was left open, meticulous closure of the muscles, fascia, subcutaneous tissue, and skin was done. Three years later, when the patient was 7 years old, she returned for treatment due to the reappearance of her preoperative symptoms. MRI was performed that showed an occipital intradiploic pseudomeningocele (Fig. 2). After this imaging was performed, the patient was lost to follow-up without undergoing revision surgery. She returned for treatment 4 years later because of the intensification of her preoperative symptoms, pins and needles with altered sensation in her limbs, which were suggestive of spinal cord dysfunction. MRI was performed that showed increased size of the intradiploic pseudomeningocele and a new cervical syrinx extending from $\mathrm{C} 2$ to $\mathrm{C} 3$ (Fig. 3). At this time the patient's neurological examination was again normal.

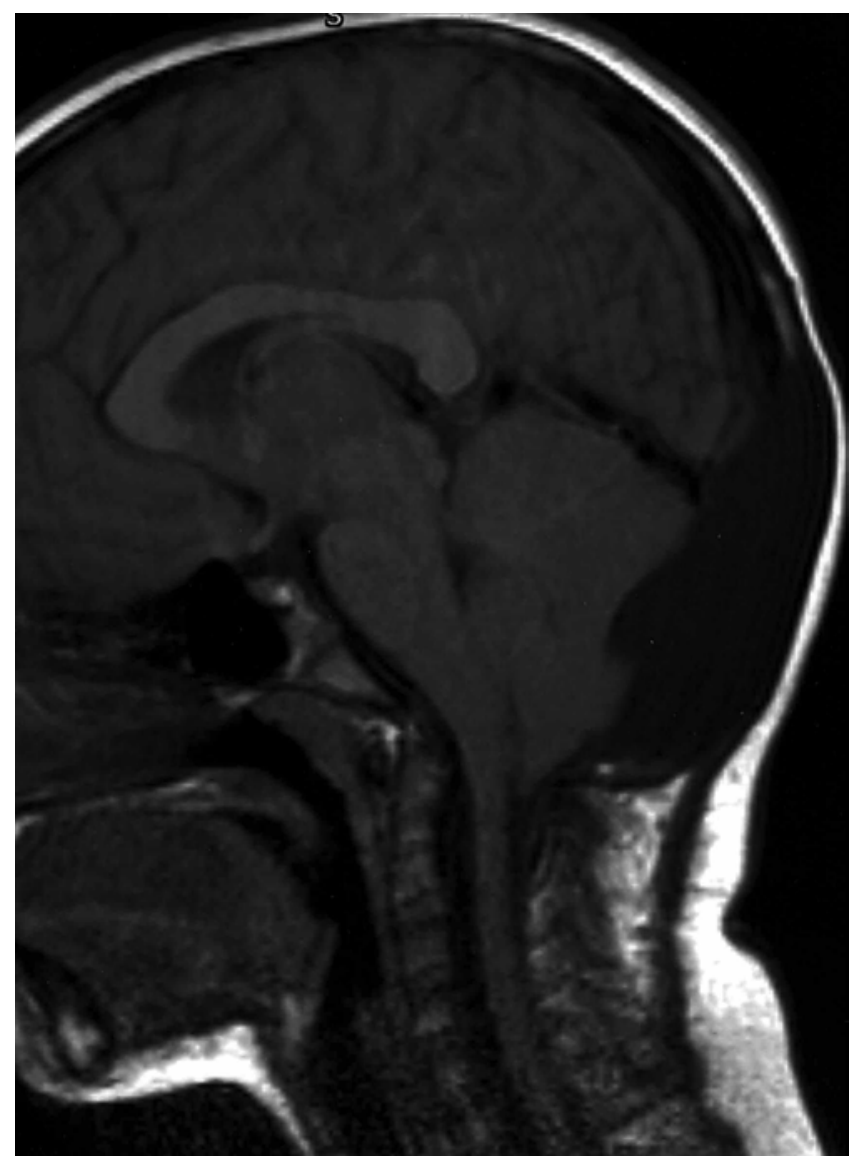

FIG. 2. Sagittal T1-weighted MR image obtained 3 years after the first operation demonstrating a hypointense occipital collection with mass effect on the cerebellum.

\section{Revision Surgeries}

The patient underwent a first revision surgery when she was 11 years old (7 years after undergoing foramen magnum decompression without dural closure). We exposed the small defect of the occipital cortical bone that had been created during the first operation. The bony defect lay directly over the small opening of the foramen of Magendie. We partially excised the inner layer of the occipital bone housing the intradiploic pseudomeningocele to restore space in the posterior fossa, and then performed arachnoid scar lysis. Meticulous wound closure in 4 layers was performed without dural closure, as in the patient's first operation.

An MRI examination performed 2 months after the first revision surgery showed worsening of the syrinx to involve the whole cervical spinal cord and spinal cord edema extending to the conus (Fig. 4). In a second revision surgery we placed a pseudomeningocele-peritoneal shunt with an adjustable pressure valve (Strata, Medtronic; pressure setting at performance level 2.5).

\section{Postoperative Course}

The patient's postoperative course was uneventful, and she was discharged home with a normal neurological examination. Her preoperative symptoms had resolved and 


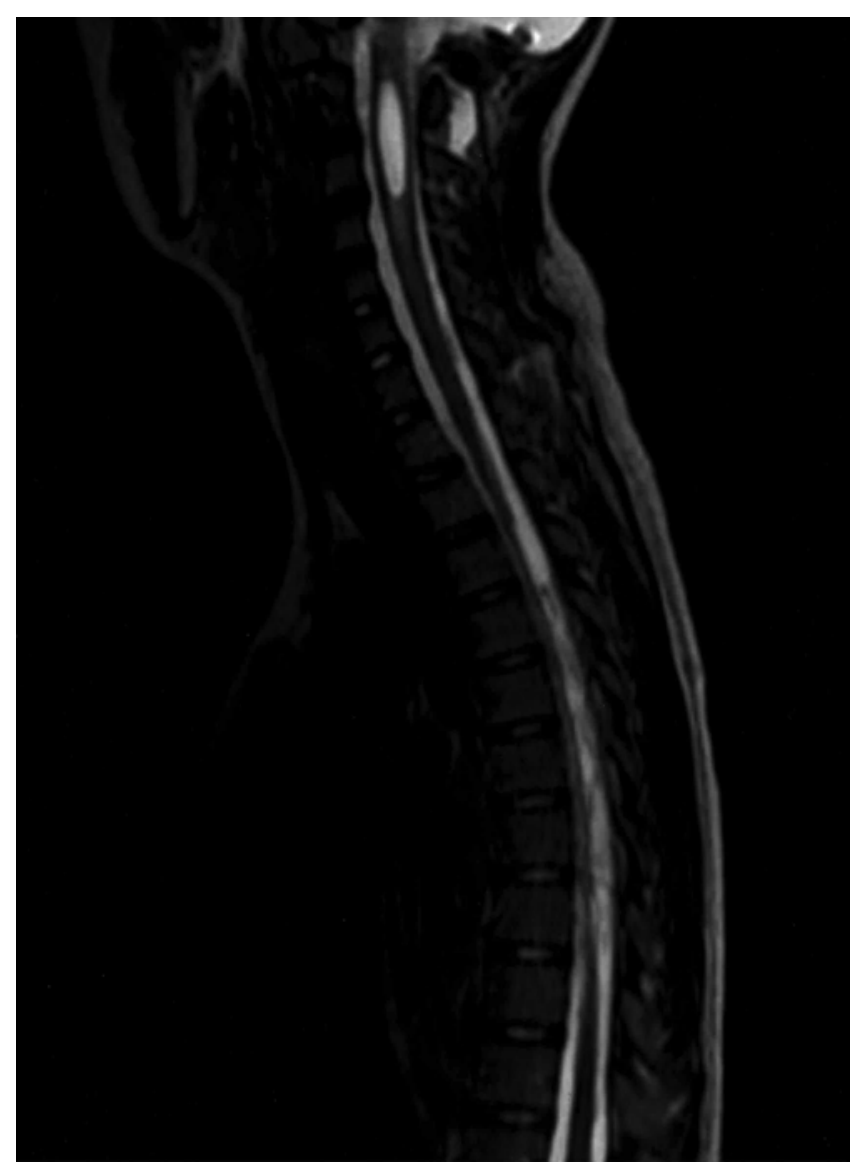

FIG. 3. Sagittal T2-weighted MR image obtained 7 years after the first operation. The hyperintense occipital fluid mass has increased and a new syrinx extending from $\mathrm{C} 2$ to $\mathrm{C} 3$ is visible.

her sensory symptoms had improved. The MRI performed 1 year after the shunt placement showed a significant decrease of the syrinx (Fig. 5).

\section{Discussion}

Multiple methods exist for decompressive surgery for symptomatic patients with Chiari I malformation. Foramen magnum decompression with or without partial removal of the posterior arch of $\mathrm{Cl}$ is generally accepted. However, there is still controversy as to whether for decompression a durotomy or a durotomy with subsequent duraplasty has to be performed in these cases. $4,6,8,12,13,15$, 20-22,36,37 Yet another option is decompressive surgery without dural repair. ${ }^{10,16}$ The bony decompression is followed by durotomy, with opening of the arachnoid and resection of visible adhesion, and the dura is then intentionally left wide open. The reason for not closing the dura is to ameliorate the CSF flow by creating a pseudomeningocele that enlarges the cisterna magna..$^{34,35}$ The use of alternative methods, such as primary dural closure, duraplasty, or a patch that is subject to failure may partly neutralize the maximal decompressive effect of the surgical procedure.

We have previously reported that in addition to the child in the present case, 6 patients with Chiari I malformation have been described thus far who postoperatively devel-

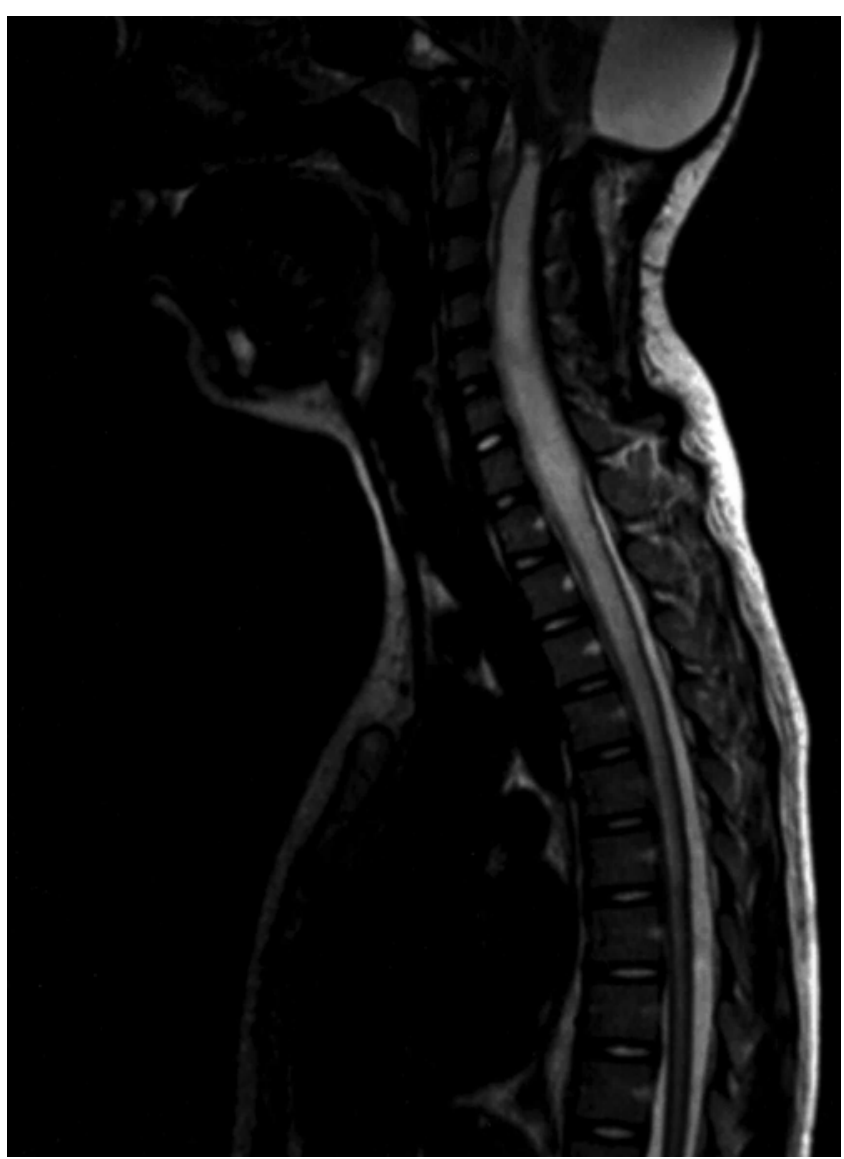

FIG. 4. Sagittal T2-weighted MR image obtained 2 months after revision surgery. The syrinx spans the whole cervical spine and edema in the spinal cord extends to the conus.

oped an occipital intradiploic pseudomeningocele..$^{18,19}$ Three of these patients had undergone surgery with duraplasty, ${ }^{3,11,23}$ and 3 without dural closure. ${ }^{18,19}$ To the best of our knowledge we present here the first report of a patient who initially developed an occipital intradiploic pseudomeningocele and then a de novo cervical syrinx following decompressive surgery for Chiari I malformation.

The formation and the size of an intradiploic pseudomeningocele might depend on the composition of the diploe at the place where it is opened on the occasion of the primary foramen magnum decompression. In this context the participation of the diploe in the draining of CSF into the venous system ${ }^{15,29,33}$ should be considered. The opened diploe comes into contact with the pulsating force of the CSF with its water hammer effect. When the diploe is opened where there is little or no CSF drainage, the internal and external layers of the occipital bone might splay, leading to the buildup of an intradiploid fluid collection. However, if the diploe is opened where there is adequate CSF drainage the diploe may not widen or may widen just a little. This mechanism might explain why the patients with a postsurgical occipital intradiploic CSF collection reported by Bulleid et al. ${ }^{3}$ and another patient we previously reported ${ }^{19}$ complained of low-pressure headaches and showed only slight splaying of the diploe.,19 


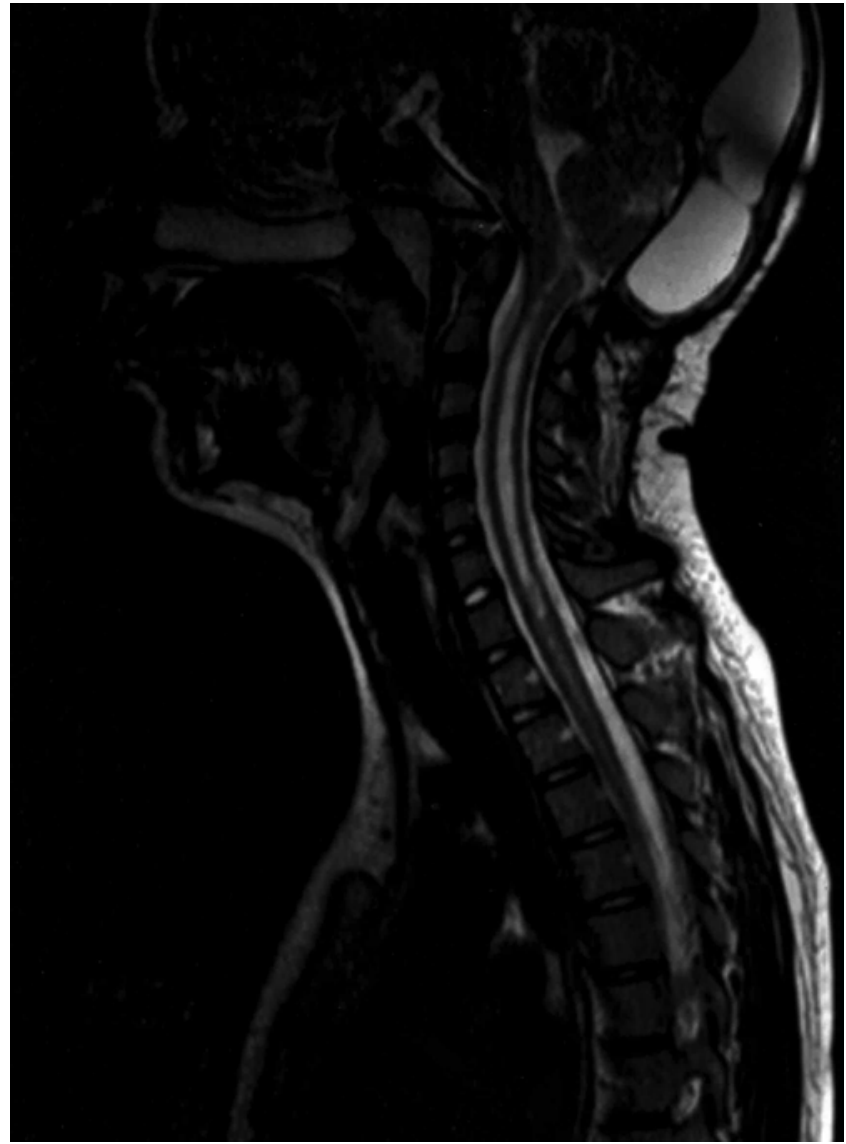

FIG. 5. Sagittal T2-weighted MR image demonstrates the diminution of the syrinx 1 year after placement of a pseudomeningocele-peritoneal shunt.

The formation of an intradiploic pseudomeningocele might be averted by meticulous sealing of the opened diploe when it is violated during the suboccipital craniectomy. But does closure of an opened diploe years later at revision surgery always resolve the clinical symptoms?

To our knowledge, only 2 patients with intravertebral CSF collections have been reported so far., ${ }^{9,18}$ Gandhoke et al. ${ }^{9}$ first reported a patient with Chiari I malformation who developed a collection of CSF in C2 after foramen magnum decompression with expansile duraplasty. This patient had been asymptomatic for 14 years. At revision surgery a dural opening that communicated with the right lamina of $\mathrm{C} 2$ was found below the former duraplasty. The surgeons closed the dural defect and reinforced the inner and outer layers of the bony cavity with demineralized bone matrix. One week after surgery the patient presented with symptoms of elevated intracranial pressure (headache, nausea, and vomiting). Imaging showed a small pseudomeningocele without ventricular enlargement. The patient's symptoms were only relieved with CSF diversion, first performed with lumbar drainage and then with a ventriculoperitoneal shunt. Gandhoke et al. ${ }^{9}$ concluded that over the years the communication between the dural opening and the intraosseous fistula had built up an accessory CSF drainage pathway that was obstructed at revision surgery. We reported elsewhere a female patient who had developed a significant intraosseous C2 CSF collection and a very small suboccipital intradiploic CSF collection. ${ }^{18}$ She complained of headaches and vomiting 5 years after Chiari I decompressive surgery. At revision surgery we filled the hollow space of $\mathrm{C} 2$ with a bioactive bone graft substitute, closed the bony defects of the suboccipital bone and $\mathrm{C} 2$ with bone wax, and resected the arachnoid adhesions. After revision surgery our patient remained asymptomatic and did not require further treatment despite the blockage of 2 potential additional sites of CSF absorption. The difference between our previously reported patient ${ }^{18}$ and the patient reported by Gandhoke et al. ${ }^{9}$ may have been that before the foramen magnum decompression Gandhoke et al.'s patient had an underlying compensated hydrocephalus that became clinically relevant after the revision surgery and led to an obstruction of the additional CSF absorption pathway that had developed over the years.

Only a few cases of iatrogenically induced syrinxes have been described so far. In 2013 Naftel et al. reported 7 pediatric patients with de novo syrinx after decompressive surgery for Chiari I malformation. ${ }^{25}$ The syrinxes occurred between 0.2 and 4.3 years after the first operation. All patients had undergone suboccipital craniectomy and $\mathrm{C} 1$ laminectomy, 4 of them had undergone tonsil resection or coagulation, and all underwent duraplasty. Operative findings at the revision surgery were described as scarred arachnoid, arachnoid webs, intradural scarring, and fibrous bands at previous C1-laminectomy sites.

The patient we present here developed a large occipital intradiploic pseudomeningocele in the first 3 years after foramen magnum decompression and then also developed a syrinx extending from $\mathrm{C} 2$ to $\mathrm{C} 3$ during the 4 th and 7 th years after the first operation. The formation of a large occipital intradiploic CSF collection may be a sign that the diploe was violated at a place where there is no or only a small amount of CSF drainage. The late induction of the syrinx over the years may have been be due to postoperative arachnoid scarring after the first surgery. Another reason for the formation of the syrinx might have been an underlying component of hydrocephalus that was not sufficiently drained by the additional intradiploic CSF draining site.

In case of hydrocephalus or elevated intracranial pressure, sealing of the opened suboccipital diploe at the primary surgery or at the first revision surgery might not have prevented the formation or the aggravation of the syrinx. The increase of the syrinx after the first revision surgery might have been due to progressive arachnoid scarring provoked by arachnoid scar lysis or the persistence of underlying hydrocephalus or elevated intracranial pressure. In this case the lysis of arachnoid adhesions might not have addressed the filling pressure of the syrinx without CSF diversion.

Although the preoperative MRI did not show radiological signs of hydrocephalus in this case, we cannot formally rule out compensated hydrocephalus. The patient did not undergo intracranial pressure monitoring. Subsequent pseudomeningocele-peritoneal shunting seems to have addressed the elevated pressure or hydrocephalus, resulting 
in the resolution of preoperative symptoms and a significant decrease of the syrinx.

\section{Conclusions}

The appearance of an intradiploic pseudomeningocele or low-pressure headache after foramen magnum decompression might be avoided by meticulous sealing of the opened diploe. The formation of a syrinx after decompressive surgery for Chiari I malformation might be an indicator of preexisting hydrocephalus or elevated intracranial pressure. Intracranial pressure monitoring in Chiari I malformation patients prior to foramen magnum decompression might detect patients who need CSF shunting.

\section{References}

1. Agrawal D, Mishra S: Post-traumatic intradiploic pseudomeningocele. Indian Pediatr 47:271-273, 2010

2. Ben Nsir A, Boubaker A, Jemel H: Syringomyelia following surgery for a spontaneous spinal subdural hematoma in a 13-year-old girl with congenital von Willebrand disease: case report and literature review. Childs Nerv Syst 32:727-731, 2016

3. Bulleid LS, Hughes T, Bhatti I, Leach PA: Low-pressure headaches following foramen magnum decompression secondary to absorption of cerebrospinal fluid into the venous system of the diploic space. Childs Nerv Syst 32:897-899, 2016

4. Chai Z, Xue X, Fan H, Sun L, Cai H, Ma Y, et al: Efficacy of posterior fossa decompression with duraplasty for patients with Chiari malformation type I: a systematic review and meta-analysis. World Neurosurg 113:357-365.e1, 2018

5. D'Almeida AC, King RB: Intradiploic cerebrospinal fluid fistula. Report of two cases. J Neurosurg 54:84-88, 1981

6. Durham SR, Fjeld-Olenec K: Comparison of posterior fossa decompression with and without duraplasty for the surgical treatment of Chiari malformation Type I in pediatric patients: a meta-analysis. J Neurosurg Pediatr 2:42-49, 2008

7. Fischer EG, Welch K, Shillito J Jr: Syringomyelia following lumboureteral shunting for communicating hydrocephalus. Report of three cases. J Neurosurg 47:96-100, 1977

8. Galarza M, Sood S, Ham S: Relevance of surgical strategies for the management of pediatric Chiari type I malformation. Childs Nerv Syst 23:691-696, 2007

9. Gandhoke GS, Hauptman JS, Salvetti DJ, Weiner GM, Panigrahy A, Yilmaz S, et al: Transosseous cerebrospinal fluid fistula 14 years after Chiari decompression: presentation and management. J Neurosurg Pediatr 16:146-149, 2015

10. Gardner WJ, Goodall RJ: The surgical treatment of ArnoldChiari malformation in adults; an explanation of its mechanism and importance of encephalography in diagnosis. J Neurosurg 7:199-206, 1950

11. Giordano M, Di Rocco C: Iatrogenic intradiploic cerebrospinal fluid collection. Childs Nerv Syst 32:787-790, 2016

12. Hankinson T, Tubbs RS, Wellons JC: Duraplasty or not? An evidence-based review of the pediatric Chiari I malformation. Childs Nerv Syst 27:35-40, 2011

13. Jiang E, Sha S, Yuan X, Zhu W, Jiang J, Ni H, et al: Comparison of clinical and radiographic outcomes for posterior fossa decompression with and without duraplasty for treatment of pediatric Chiari I malformation: a prospective study. World Neurosurg 110:e465-e472, 2018

14. Johnston I, Jacobson E, Besser M: The acquired Chiari malformation and syringomyelia following spinal CSF drainage: a study of incidence and management. Acta Neurochir (Wien) 140:417-428, 1998

15. Johnston KD, Walji AH, Fox RJ, Pugh JA, Aronyk KE: Ac- cess to cerebrospinal fluid absorption sites by infusion into vascular channels of the skull diplö. J Neurosurg 107:841843, 2007

16. Krieger MD, McComb JG, Levy ML: Toward a simpler surgical management of Chiari I malformation in a pediatric population. Pediatr Neurosurg 30:113-121, 1999

17. Kumar R, Chandra SP, Sharma BS: Giant intradiploic pseudomeningocele of occipital bone. J Neurosurg Pediatr 9:82-85, 2012

18. Kurzbuch AR, Magdum S: Constant dripping wears away the bone: intraosseous $\mathrm{C} 2$ and suboccipital intradiploic cerebrospinal fluid collection after Chiari I decompressive surgery. Acta Neurochir (Wien) 159:1999-2002, 2017

19. Kurzbuch AR, Magdum S, Jayamohan J: Intradiploic pseudomeningocele and ossified occipitocervical pseudomeningocele after decompressive surgery for Chiari I malformation: report of two cases and literature review. Neurosurg Rev 40:345-350, 2017

20. Lee A, Yarbrough CK, Greenberg JK, Barber J, Limbrick DD, Smyth MD: Comparison of posterior fossa decompression with or without duraplasty in children with Type I Chiari malformation. Childs Nerv Syst 30:1419-1424, 2014

21. Lin W, Duan G, Xie J, Shao J, Wang Z, Jiao B: Comparison of results between posterior fossa decompression with and without duraplasty for the surgical treatment of Chiari malformation type I: a systematic review and meta-analysis. World Neurosurg 110:460-474.e5, 2018

22. Lu VM, Phan K, Crowley SP, Daniels DJ: The addition of duraplasty to posterior fossa decompression in the surgical treatment of pediatric Chiari malformation type I: a systematic review and meta-analysis of surgical and performance outcomes. J Neurosurg Pediatr 20:439-449, 2017

23. Mahaney KB, Menezes AH: Intradiploic occipital pseudomeningocele in a patient with remote history of surgical treatment of Chiari malformation. J Neurosurg Spine 21:769-772, 2014

24. Miao TL, Joswig H, Pandey SK, Parrent AG: Intradiploic cerebrospinal fluid cyst following occipital encephalocele surgery in patient with Dandy-Walker malformation. World Neurosurg 117:66-67, 2018

25. Naftel RP, Tubbs RS, Menendez JY, Wellons JC III, Pollack IF, Oakes WJ: Worsening or development of syringomyelia following Chiari I decompression: case report. J Neurosurg Pediatr 12:351-356, 2013

26. Padmanabhan R, Crompton D, Burn D, Birchall D: Acquired Chiari 1 malformation and syringomyelia following lumboperitoneal shunting for pseudotumour cerebri. J Neurol Neurosurg Psychiatry 76:298, 2005

27. Peyser E, Weissberg D: Post-traumatic arachnoidal cyst. Report of an unusual case. J Neurosurg 18:551-553, 1961

28. Placantonakis DG, Lis E, Souweidane MM: Intradiploic cerebrospinal fluid fistulas of iatrogenic origin. Report of two cases. J Neurosurg 104 (5 Suppl):356-359, 2006

29. Pugh JA, Tyler J, Churchill TA, Fox RJ, Aronyk KE: Intraosseous infusion into the skull: potential application for the management of hydrocephalus. J Neurosurg 106 (2 Suppl):120-125, 2007

30. Riffaud L, Moughty C, Henaux PL, Haegelen C, Morandi $\mathrm{X}$ : Acquired Chiari I malformation and syringomyelia after valveless lumboperitoneal shunt in infancy. Pediatr Neurosurg 44:229-233, 2008

31. Sato TS, Moritani T, Hitchon P: Occipital intradiploic CSF pseudocyst: an unusual complication of a ventriculoperitoneal shunt malfunction. AJNR Am J Neuroradiol 30:635636, 2009

32. Scholsem M, Scholtes F, Belachew S, Martin D: Acquired tonsillar herniation and syringomyelia after pleural effusion aspiration: case report. Neurosurgery 62:E1172-E1173, 2008 
33. Tsutsumi S, Ogino I, Miyajima M, Ito M, Arai H, Yasumoto Y: Cerebrospinal fluid drainage through the diploic and spinal epidural veins. J Anat 227:297-301, 2015

34. Williams B: A blast against grafts-on the closing and grafting of the posterior fossa dura. Br J Neurosurg 8:275-278, 1994

35. Williams B: Syringomyelia. Neurosurg Clin N Am 1:653685,1990

36. Xu H, Chu L, He R, Ge C, Lei T: Posterior fossa decompression with and without duraplasty for the treatment of Chiari malformation type I-a systematic review and meta-analysis. Neurosurg Rev 40:213-221, 2017

37. Zhao JL, Li MH, Wang CL, Meng W: A systematic review of Chiari I malformation: techniques and outcomes. World Neurosurg 88:7-14, 2016

\section{Disclosures}

The authors report no conflict of interest concerning the materials or methods used in this study or the findings specified in this paper.

\section{Author Contributions}

Conception and design: both authors. Acquisition of data: both authors. Drafting the article: Kurzbuch. Critically revising the article: Magdum. Reviewed submitted version of manuscript: both authors. Approved the final version of the manuscript on behalf of both authors: Kurzbuch.

\section{Correspondence}

Arthur R. Kurzbuch: Hôpital du Valais, Centre Hospitalier du Valais Romand (CHVR), Hôpital de Sion, Switzerland. kurzbuch@web.de. 